\title{
Reducing the sodium content of high-salt foods: Effect on cardiovascular disease in South Africa
}

\author{
Melanie Y Bertram, Krisela Steyn, Edelweiss Wentzel-Viljoen, Stephen Tollman, Karen J Hofman
}

Background. Average salt intake in South African (SA) adults, $8.1 \mathrm{~g} /$ day, is higher than the $4-6 \mathrm{~g} /$ day recommended by the World Health Organization. Much salt consumption arises from non-discretionary intake (the highest proportion from bread, with contributions from margarine, soup mixes and gravies). This contributes to an increasing burden of hypertension and cardiovascular disease (CVD).

Objectives. To provide SA-specific information on the number of fatal CVD events (stroke, ischaemic heart disease and hypertensive heart disease) and non-fatal strokes that would be prevented each year following a reduction in the sodium content of bread, soup mix, seasoning and margarine.

Methods. Based on the potential sodium reduction in selected products, we calculated the expected change in population-level systolic blood pressure (SBP) and mortality due to CVD and stroke.

Results. Proposed reductions would decrease the average salt intake by $0.85 \mathrm{~g} /$ person/day. This would result in 7400 fewer CVD deaths and 4300 less non-fatal strokes per year compared with 2008. Cost savings of up to R300 million would also occur.

Conclusion. Population-wide strategies have great potential to achieve public health gains as they do not rely on individual behaviour or a well-functioning health system. This is the first study to show the potential effect of a salt reduction policy on health in SA.

S Afr Med J 2012;102(9):743-745. DOI:10.7196/SAMJ.5832
South Africa (SA) confronts a quadruple burden of disease, with the chronic non-communicable disease (NCD) burden increasing in the face of high levels of HIV, injuries and maternal and child health issues. Chronic diseases contributed nearly one-third of all disabilityadjusted life years (DALYs) in SA in 2000. ${ }^{1}$ Despite this, NCDs are often neglected in health priorities. Stroke is the third-leading cause of death in SA, after HIV and ischaemic heart disease. ${ }^{1}$

The SA Hypertension Guidelines recommend a maximum salt intake of $6 \mathrm{~g} /$ day; ${ }^{2}$ this is the upper boundary of the $4-6 \mathrm{~g} /$ day recommended by the World Health Organization (WHO). ${ }^{3}$ SA diet is high in salt, with bread contributing to 25 - $40 \%$ of sodium intake. ${ }^{4}$ Average daily intake, measured by 24 -hour urinary sodium excretion, is $7.8 \mathrm{~g}$ in black persons, $8.5 \mathrm{~g}$ in mixed-race persons, and $9.5 \mathrm{~g}$ in white persons in SA. ${ }^{4}$

The SA health system functions poorly; queues, lack of care continuity and drug stock-outs contribute to a lack of preventive healthcare. ${ }^{5}$ Although new policies and programmes to revitalise

Medical Research Council/Wits Rural Public Health and Health Transitions Research Unit (Agincourt), and Health and Population Division, School of Public Health, Faculty of Health Sciences, University of the Witwatersrand, Johannesburg Melanie Y Bertram, BBioMedSci, Grad Cert Health Econ, PhD Stephen Tollman, BSc, MMed, MA, MPH, PhD Karen J Hofman, MB BCh, FAAP

Chronic Disease Initiative in Africa, Department of Medicine, Faculty of Health Sciences, University of Cape Town

Krisela Steyn, MSc, MD

Centre of Excellence for Nutrition, Faculty of Health Sciences, North-West University, Potchefstroom

Edelweiss Wentzel-Viljoen, $\mathrm{PhD}, \mathrm{RD}(\mathrm{SA})$

INDEPTH Network, Accra, Ghana, and Centre for Global Health Research, Umeå University, Sweden

Stephen Tollman, BSc, MMed, MA, MPH, PhD primary healthcare and a national health insurance scheme are gaining momentum, these changes will take time and health gains will not be immediate. Tangible health benefits can be achieved through intersectoral actions, i.e. collaboration between the Department of Health (DoH) and other government departments to shape food policy, road safety and alcohol taxation. This should be investigated in the SA context.

Salt is known to affect blood pressure (BP) via a linear association. ${ }^{6}$ This analysis provides evidence on the number of cardiovascular disease (CVD) deaths and non-fatal strokes likely to be avoided if the sodium content of bread, margarine, soups and gravies was reduced.

\section{Methods}

Average salt intake in SA was previously reported in $2005 .{ }^{4}$ Statistics SA 2010 mid-year population statistics showed that the SA population was $79 \%$ black, $11 \%$ mixed race and $9 \%$ white. ${ }^{7}$ Using these data, we calculated the weighted average salt intake across the population. Consumption and weighted average intake of bread, margarine, gravy and soup was determined according to race (Table 1).

A study undertaken with Sasko Milling and Baking found that it was possible to produce bread with a sodium content of $342 \mathrm{mg} / 100 \mathrm{~g}$, without affecting texture or taste. ${ }^{8}$ Similar work with Unilever indicated that it was possible to reduce the sodium content of margarine by $61 \%$, soup mix by $69 \%$ and seasoning by $51 \% .^{9}$ We calculated the change in sodium intake if these reductions were adopted in SA and used a regression equation ${ }^{10}$ to calculate the effect on the population distribution of BP. For each $100 \mathrm{mmol}$ reduction in sodium intake, an SBP reduction of $5-10 \mathrm{mmHg}$ is expected, with variation according to age. ${ }^{10}$ Norman et al. ${ }^{11}$ published current population distributions of BP, corrected for regression dilution bias.

The potential impact fraction (PIF) (Equation 1), employed in the South African and WHO comparative risk assessments, estimates the reduction in morbidity and mortality anticipated if exposure to common risk factors were to be reduced. ${ }^{11}$ We used the PIF to estimate the percentage reduction in CVD that would result from reducing the sodium content of the described foods to the levels highlighted, considering the altered population distribution of SBP and relative risks adapted from the Prospective Studies Collaboration. ${ }^{11}$ The PIF 
Table 1. Intake of high-salt foods in SA in $2005^{4}$

\begin{tabular}{lllll}
\hline & \multicolumn{4}{c}{ Salt intake per product (\%) } \\
\cline { 2 - 5 } & Bread & $\begin{array}{l}\text { Soup } \\
\text { powder }\end{array}$ & Seasoning & Margarine \\
\hline Black & 40.5 & 2.9 & 1.1 & 2.9 \\
Mixed race & 30.7 & N/A & N/A & 1.9 \\
White & 25.2 & N/A & N/A & 2.7 \\
$\begin{array}{l}\text { Weighted } \\
\begin{array}{l}\text { average intake } \\
\text { (population) }\end{array}\end{array}$ & 38.0 & 2.3 & 0.9 & 2.8 \\
N/A= not applicable. & & & & \\
& & & &
\end{tabular}

was calculated separately for stroke, ischaemic heart disease and hypertensive heart disease. The PIF values were used to calculate the consequent number of CVD deaths and non-fatal strokes that could be avoided annually. The PIF was multiplied by the total number of deaths due to each condition ${ }^{1}$ and the number of new incident strokes. ${ }^{13}$

$$
P I F=\frac{\int_{l}^{h} R R(x) P(x) d x-\int_{l}^{h} R R(x) P^{*}(x) d x}{\int_{l}^{h} R R(x) P(x) d x}
$$

Equation 1. Potential impact fraction (PIF). $\mathrm{P}(\mathrm{x})$ is the original risk factor distribution, $\mathrm{P}^{*}(\mathrm{x})$ is the risk factor distribution after the change, $\mathrm{RR}(\mathrm{x})$ is the relative risk function, $\mathrm{dx}$ denotes that the integration is performed with respect to $\mathrm{x}$, and $\mathrm{l}$ and $\mathrm{h}$ are integration boundaries. ${ }^{12}$

\section{Results}

The average sodium intake from bread in SA is $1.6 \mathrm{~g} /$ person/day; a reduction of $0.73 \mathrm{~g} /$ person/day would result from a decrease in the sodium content of bread from $650 \mathrm{mg} / 100 \mathrm{~g}$ to $350 \mathrm{mg} / 100 \mathrm{~g}$. This reduction would increase to $0.85 \mathrm{~g} /$ person/day if the sodium content of margarine, soup and seasoning was lowered as well. The effect of this sodium intake on population SBP varies by age and sex. Fig. 1 shows the projected shift in BP distribution for the youngest and oldest age groups.

Applying the PIF values to the total number of fatal and non-fatal incident strokes estimated in $2008,{ }^{13}$ we estimated that 7400 deaths would be prevented in SA each year - 6400 from reducing the sodium content of bread alone (Fig. 2). This includes deaths related to stroke (2900), ischaemic heart disease (2 500) and hypertensive heart disease (2 000). Furthermore, approximately 4300 nonfatal strokes would be prevented. Overall, $8 \%$ of strokes, $6.5 \%$ of ischaemic heart disease and $11 \%$ of hypertensive heart disease could be prevented.

\section{Discussion}

Reducing the sodium content of food has the potential for large public health effects. As well as preventing 7400 CVD deaths per year, the prevention of non-fatal strokes will relieve pressure on the overburdened health system. Data indicate that the direct costs of treating a stroke amount to R76 000 (excluding follow-up and rehabilitation costs; ${ }^{14}$ translated to 2010 ZAR). This amounts to a total annual saving of R300 million (40 million USD) due to the prevention of non-fatal strokes. This does not include household costs, such as lost income, which can be significant. Reducing the sodium content of bread is of greatest importance, with $80 \%$ of estimated cost savings stemming from this alone.

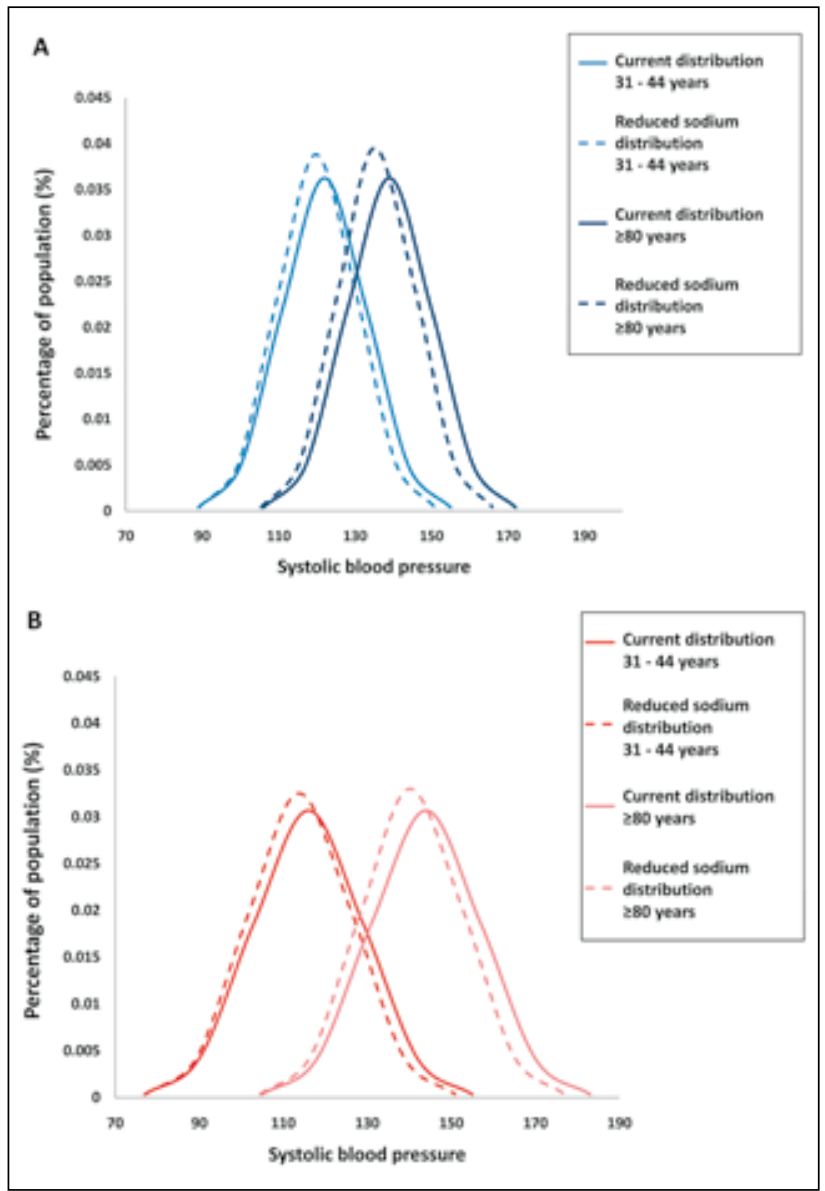

Fig. 1. Expected change in population distribution of SBP due to a sodium content reduction of bread, soup mix and seasoning, in (A) males and (B) females. Solid lines represent the current distribution; dashed lines represent new distribution due to the change.

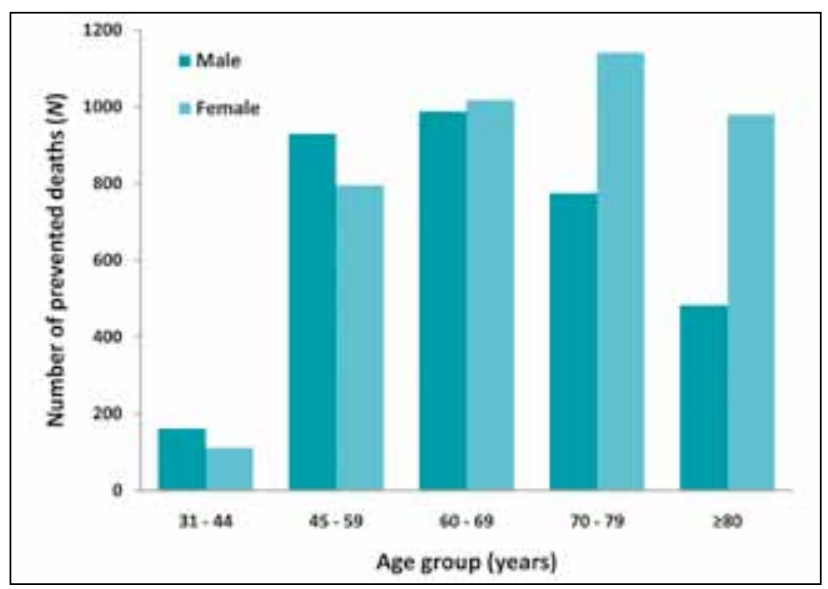

Fig. 2. Number of CVD deaths prevented per year due to a reduction in the sodium content of foods in $S A$.

These values may underestimate the true effect of reduced sodium intake on stroke, as an independent effect not mediated via BP has been hypothesised $;{ }^{15}$ the evidence is not yet strong enough to support an independent assessment of this effect. Our analysis did not account for the possibility that the effect of sodium reduction may be greater in black individuals than in white individuals. ${ }^{16}$ Furthermore, our analysis assumed that the consumption of other high-salt foods would not increase if the salt content of targeted foods was decreased. A previous 
randomised trial showed no change in bread consumption or choice of sandwich fillings following a reduction in the bread's sodium content. ${ }^{17}$ Our study also assumes that regulations concerning sodium levels would affect all commercially available products.

The cost of baking a regular loaf of brown bread was 92.3 cents per loaf in 2005.9 The additional cost of reducing sodium content was estimated at 8.91 cents per loaf; ${ }^{9}$ this amount could not be attributed solely to sodium reduction, however, as other micronutrient content was simultaneously increased. An updated study of the cost implications is required.

We excluded from our analysis a controversial observational study ${ }^{18}$ that showed an inverse relationship between sodium intake and cardiovascular mortality - contradicting the previously accepted relationship. Furthermore, the study was criticised for missing data, employing only one measurement of sodium intake and failing to account for confounding factors. ${ }^{19}$

Evidence indicates that a reduced sodium diet has an effect on hypertension equivalent to first-line drug treatment with a diuretic or beta-blocker. ${ }^{20}$ Individual measures to reduce sodium intake, such as dietary counselling, can affect SBP levels, although to a limited degree because most salt intake is derived from pre-prepared food. ${ }^{21}$ Population-wide strategies to reduce nondiscretionary salt intake, and thereby reduce the population distribution of BP, are expected to have an overall larger effect on population health at lower cost. ${ }^{22}$

Voluntary measures to reduce the sodium content of packaged food have been introduced successfully in several countries. ${ }^{23}$ The European Union currently has 11 countries signed up to a salt reduction programme. The Consensus Action on Salt in Health (CASH) group in the United Kingdom has been successful in convincing a number of major retailers to reduce the sodium content of pre-packaged foods by $10-15 \%{ }^{23}$ In contrast, an Australian study indicated that 20 times the health gain seen through voluntary changes regarding salt content could be achieved through mandatory legislative changes. ${ }^{22}$ However, sodium tax - an economic (dis) incentive intended to alter food-purchasing behaviour and thereby decrease sodium intake - was estimated to achieve a smaller reduction in intake than mandatory changes, with consequently smaller health effects. ${ }^{24}$

We applaud the efforts of the DoH to engage with the appropriate consumer and industry groups to begin the process of a voluntary reduction in food sodium levels. Engagement with companies producing cereals, gravies and soup mixes, consumed in high quantities in SA, is needed for a comprehensive salt reduction plan. Industry concerns regarding consumer acceptance of lower-sodium products are unwarranted. Evidence indicates that the palate adapts to lower-sodium foods, particularly if the salt content is reduced incrementally in small steps to a desired level, ${ }^{25}$ allowing for taste adaptation. The DoH intends to implement appropriate policy using multiple targets over a number of years, with a concurrent monitoring and evaluation programme to ensure regulation compliance.

Acknowledgements. We acknowledge close relationships with policy makers developed through the Priority Cost Effective Lessons for Systems
Strengthening (PRICELESS)-SA project and engagements with the DoH. Funding is acknowledged from the Bill \& Melinda Gates Foundation through the Disease Control Priorities Network (DCPN) project grant to the Department of Global Health at the University of Washington, and the Fogarty International Centre and the United States National Institutes of Health. Funding sources had no role in study design, reporting and data collection, analysis and interpretation.

\section{References}

1. Norman R, Bradshaw D, Schneider M, Pieterse D, Groenewald P. Revised Burden of Disease Estimates for the Comparative Risk Factor Assessment, South Africa 2000. Cape Town: Medical Research Council, 2006. Seedat YK, Croasdale MA, Milne FJ, et al. Joint National Hypertension Guideline Working Group 2006. South African Hypertension Guidelines. S Afr Med J 2006;96:337-362.

3. World Health Organization. Diet, Nutrition and the Prevention of Chronic Disease. Geneva: WHO, 2003. http://www.who.int/hpr/NPH/docs/who_fao_expert_report.pdf. 2003 (accessed 26 May 2011).

Charlton KE Steyn $K$, Levitt NS, et al Diet and blood pressure in South Africa: intake of foods Cood

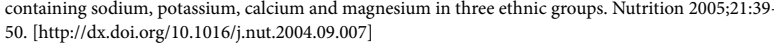

5. Goudge I Gilson L, Russell S, Gubility a Affordability, availability and acceptability barriers to health care for the chronically ill: Longitudinal case studies from South Africa. BMC Health Serv Res 2009;9(1):1-18. [http://dx.doi.org/10.1186/1472-6963-9-75]

6. He FJ, MacGregor GA. Effect of modest salt reduction on blood pressure: a meta-analysis of randomized trials. Implications for public health. J Human Hypert 2002;16:761-770.

7. Statistics South Africa. Mid-year population estimates. Pretoria: SSA, 2010. http://www.statssa.gov.za/ keyindicators/keyindicators.asp (accessed 5 November 2010).

8. Charlton KE, MacGregor E, Vorster NH, Levitt NS, Steyn K. Partial replacement of $\mathrm{NaCl}$ can be achieved with potassium, magnesium and calcium salts in brown bread. Int J Food Sci Nutr 2007;58:508-521. [http://dx.doi.org/10.1080/09637480701331148]

9. Charlton KE. The development of a dietary intervention to modify dietary cation content and the evaluation of its effects on blood pressure in hypertensive black South Africans. Cape Town: University of Cape Town, 2007.

10. Law MR, Frost CE, Wald NJ. By how much does dietary salt reduction lower blood pressure? 1-Analysis of observational data among populations. BMJ 1991;302:811-815.

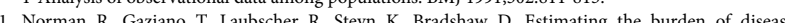
attributable to high blood pressure in South Africa in 2000. S Afr Med J 2007;97:692-698.

12. Barendregt JJ, Veerman J. Categorical versus continuous risk factors and the calculation of potential Barendregt JJ, Veerman J. Categorical versus continuous risk factors and the calculation of potential
impact fractions. J Epidemiol Community Health 2010;64:209-212. [http://dx.doi.org/10.1136/ jech.2009.090274]

3. Bertram MY, Katzenellenbogen J, Bradshaw D, Vos T, Hofman K. The disability adjusted life years due to stroke in South Africa in 2008. Int J Stroke (in press).

14. Gaziano TA, Steyn K, Cohen DJ, Weinstein MC, Opie LH. Cost-effectiveness analysis of hypertension guidelines in South Africa: Absolute risk versus blood pressure level. Circulation 2006;112:3569-4576. [http://dx.doi.org/10.1161/CIRCULATIONAHA.105.535922]

15. Perry IJ, Beevers DG. Salt intake and stroke: a possible direct effect. J Human Hypert 1992;6(1):23-25. 6. He FJ, Markandu ND, Sagnella GA, MacGregor GA. Importance of the renin system in determinin blood pressure fall with salt restriction in black and white hypertensives. Hypertension 1998;32:820-824.

7. Bolhuis DP, Temme EHM, Koeman FT, Noort MWJ, Kremer S, Janssen AM. A Salt reduction of $50 \%$ in bread does not decrease bread consumption or increase sodium intake by the choice of sandwich in bread does not decrease bread consumption or increase sodium intake by the
fillings. J Nutr 2011;141(12):2249-2255. [http://dx.doi.org/10.3945/jn.111.141366]

18. Stolarz-Strzypek K, Kuznetsova T, Thujs $L$, et al. Fatal and nonfatal outcomes, incidence of hypertension, Stolarz-Strzypek K, Kuznetsova T, Thujs L, et al. Fatal and nonfatal outcomes, incidence of hypertension,
and blood pressure changes in relation to urinary sodium excretion. JAMA 2011;305:1777-1785. [http://dx.doi.org/10.1001/jama.2011.574]

19. The Editor. Salt and cardiovascular disease mortality. Lancet 2011;377:1626. [http://dx.doi. org/10.1016/S0140-6736(11)60657-0]

20. MacGregor GA, Markandu ND, Best FE et al. Double-blind randomised crossover trial of moderate sodium restriction in essential hypertension. Lancet 1982;319:351-355. [http://dx.doi.org/10.1016/ S0140-6736(82)91389-7]

21. Hooper L, Bartlett C, Davey Smith G, Ebrahim S. Advice to reduce dietary salt for prevention of cardiovascular disease. Cochrane Database Syst Revs 2004;1.

22. Cobiac LJ, Vos T, Veerman JL. Cost-effectiveness of interventions to reduce dietary salt intake. Heart 2010. [http://dx.doi.org/10.1136/hrt.2010.199240]

23. He FJ, MacGregor GA. A comprehensive review on salt and health and current experience of worldwide salt reduction programmes. J Human Hypert 2009;23:363-384. [http://dx.doi.org/10.1038/ jhh.2008.144]

24. Smith-Spangler C, Juusola JL, Enns EA, Owens DK, Garber AM. Prevention strategies to decrease sodium intake and the burden of cardiovascular disease. A cost-effectiveness analysis. Ann Int Med 2010;152:481-487.

25. Blais CA, Borhani NO, Ferell MF, Prineas RJ, Laing B. Effect of dietary sodium restriction on taste responses to sodium choloride: a longitudinal study. Am J Clin Nutr 1986;44:232-243. 